authors, by considering changes in the intake of imported fruit only, have underestimated changes in consumption of the full range of fruits and vegetables known to have significant cardioprotective effects. ${ }^{3}$ The introduction of a market economy had major consequences for domestic production and the retail sector. There has been large investment in agriculture, with central European producers now integrated with wider European agricultural production. Much nontraditional produce is now grown locally, and fruits and vegetables are available to consumers throughout the year. Consequently, to capture the full impact of changing availability of food since the 1990s, the changes in both the total and the seasonal consumption of all fruits and vegetables need to be taken into account.

Zatonski and Willett also show that it is possible to achieve quite remarkable reductions in deaths from cardiovascular disease over a short period. Yet, in Poland, this has been achieved mainly by economic and agricultural policies, and not health policies. In contrast, policies advocated by health ministries, exemplified by the English white paper Choosing Health (www.dh.gov.uk), remain focused on medical models of education and behaviour change, even though these have had little impact on rising rates of unhealthy diets and obesity.

The health gains achieved in Poland, however, may be threatened. The European Union's Common Agricultural Policy, introduced in the 1950s, is a major determinant of what people in Europe eat ${ }^{4}$ but fails to produce the range of foods that would allow the EU population to meet basic healthy eating guidelines. ${ }^{5}$ As Poland and others implement the Common Agricultural Policy-following accession to the EU in 2004they risk suffering the consequences of policy that places large scale agricultural production and economics above health. Studies in some countries, such as Slovenia and Sweden, have shown numerous adverse health effects of the Common Agricultural Policy, including the externalised costs on non-communicable diseases and obesity through subsidies for production and consumption of animal fats, tobacco and alcohol, and insufficient supply of fruits and vegetables. ${ }^{5}$ Reform of the policy is again high on the political agenda. However, current debates about the EU budget between the UK prime minister, Tony Blair, and the French president, Jacques Chirac, are characterised more by political horse trading than the possibility of supporting poor and rural populations while also improving the diet and health of all Europeans.

Competing interests: None declared.

\footnotetext{
1 Zatonski W, Willett W. Changes in dietary fat and declining coronary heart disease in Poland: population based study BMJ 2005;331:187-8.

heart disease in Poland: population based study BMJ 2005;331:187-8. trends in cardiovascular disease risk factors in the Czech Republic, 19851992. J Epidemiol Community Health 1997:51:272-7.

3 Lock K, Pomerleau J. Fruit and vegetables in the European Union: its effect on the burden of cardiovascular disease. Brussels: European Heart Network, 2005.

4 Lock K, ed. Integrating public health with European agriculture and food policy. Eurohealth 2004;10(1):1-30.

Lobstein T. Suppose we all ate a healthy diet? Eurohealth 2004;10(1): 8-12.
}

\title{
Lung cancer mortality at ages 35-54 in the European Union: ecological study of evolving tobacco epidemics
}

\author{
Joanna Didkowska, Marta Manczuk, Ann McNeill, John Powles, Witold Zatonski
}

Epidemiological analyses indicate that disease attributable to smoking is a leading contributor to the large gap in premature mortality between the 15 countries that formerly made up the European Union and the new member states from central and eastern Europe. ${ }^{1}$ However, the prevalence of smoking in most countries has not been measured in a sufficiently consistent way, or over a long enough period, to be used to predict trends in diseases caused by smoking.

\section{Participants, methods, and results}

Lung cancer mortality can provide a useful measure of a population's exposure to smoking, ${ }^{23}$ especially the population segment aged 35-54, when around 80-90\% of cases are caused by smoking. We used trends, for each sex, in age standardised mortality due to lung cancer for ages 35-54 to map the lagged effects of the smoking epidemic in the 15 original EU member states and new members from central and eastern Europe, and to infer the earlier trends in tobacco exposure. We calculated death rates, using five year age groups, from deaths attributed to lung cancer in national data and population estimates submitted to the World Health
Organization (http://www3.who.int/whosis/mort/text/ download.cfm?path $=$ whosis,mort,mort_download\& language $=$ English $)$.

Most EU countries, including all new member states from central and eastern Europe, are now experiencing falling death rates from lung cancer in men. Four countries are, however, exempt from this favourable trend: Portugal, Greece, Spain, and France show no evidence of a decline across the 35-54 age range (figure).

Mortality from lung cancer in women is still rising in most EU countries, except for the United Kingdom and, to some extent, Ireland and Denmark. The greatest increases in the past decade were observed in France, Spain, and Hungary; the estimated annual percentage changes are $7.2 \%, 6.8 \%$, and $6 \%$, respectively. In Latvia, Lithuania, Spain, and Portugal, death rates due to lung cancer remain very low. Rates for women in Hungary exceed those for women in all other member states (mirroring those for Hungarian men) and also exceed the rates for men in more than half the states in the EU. In three countries, lung cancer rates among women are the same as or higher than those
Cancer

Centre-Institute of Oncology, Cancer Epidemiology and Prevention Division, 5 Roentgena Str, 02-781 Warsaw, Poland

Joanna Didkowska senior research fellow Marta Manczuk junior research fellow Witold Zatonski director

University College London, London WC1E 6BT

Ann McNeill honorary senior research fellow

Department of Public Health and Primary Care, Institute of Public Health, Cambridge CB2 2SR

John Powles senior lecturer Correspondence to: W Zatonski canepid@coi.waw.p

BMJ 2005;331:189-92 


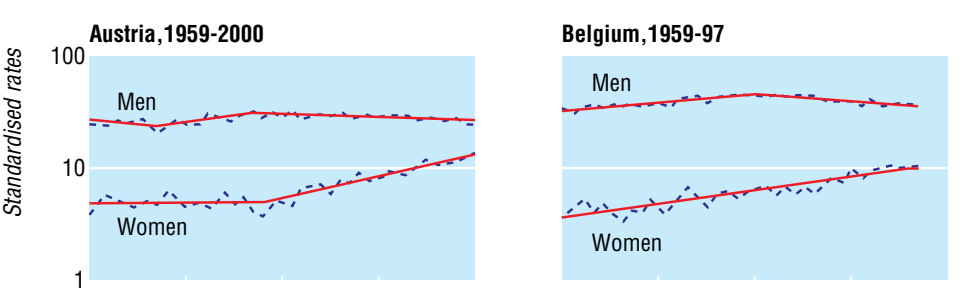

Estonia,1981-2000
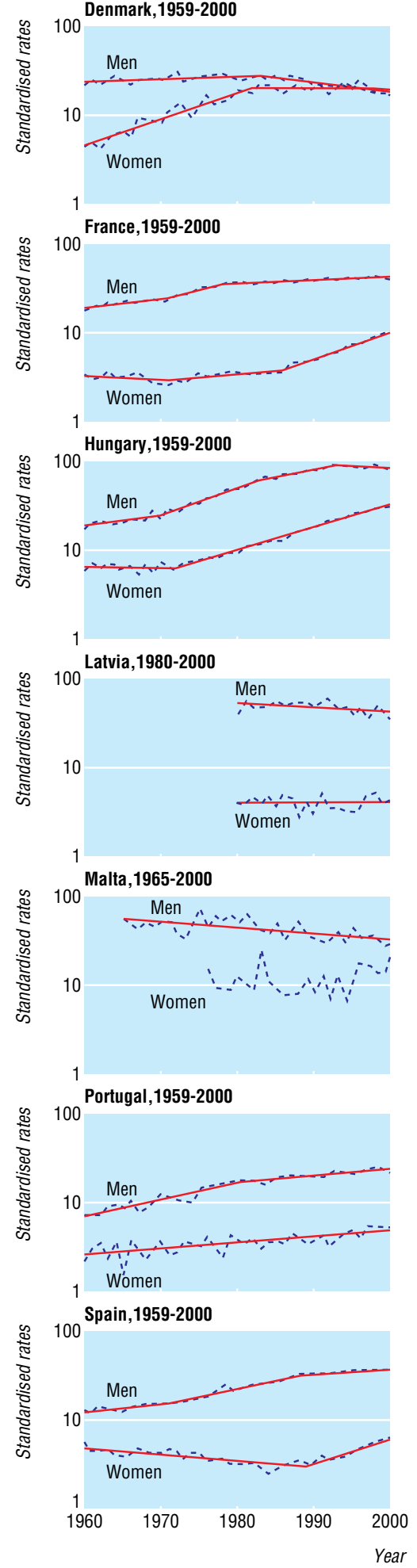

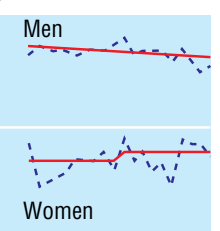

\section{Germany,1971-2000}

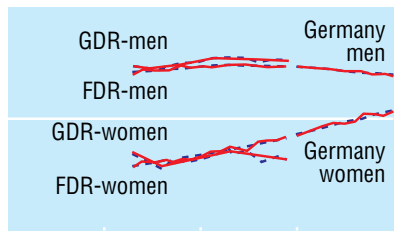

Ireland,1959-2000

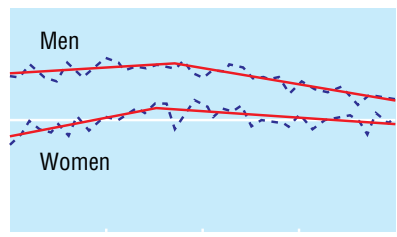

\section{Lithuania,1981-2000}

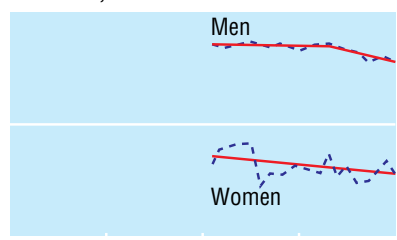

Netherlands, 1959-2000

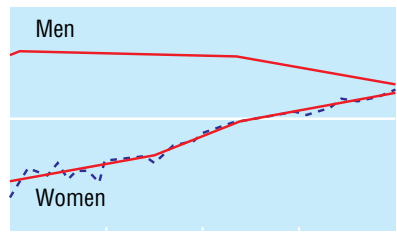

\section{Slovakia,1971-2000}

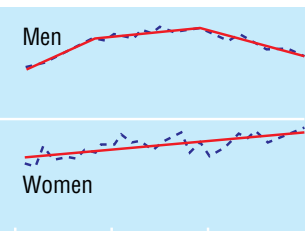

\section{Sweden,1959-2000}

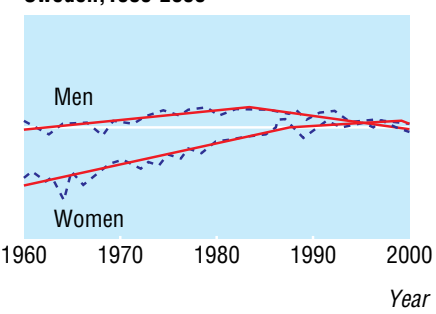

Czech Republic,1970-2000

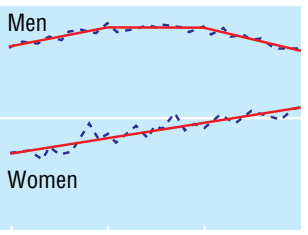

Finland, 1959-2000

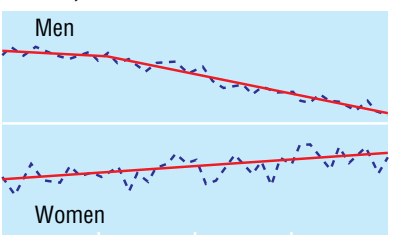

Greece,1961-2000

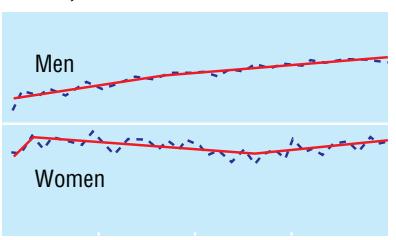

\section{Italy, 1959-2000}

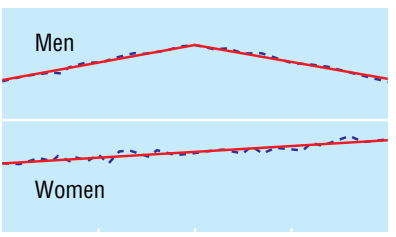

\section{Luxembourg,1967-2000}

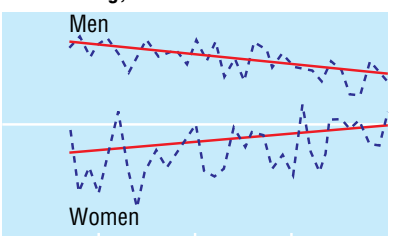

Poland,1959-2000

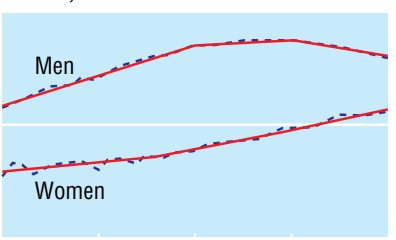

Slovenia, 1985-2000

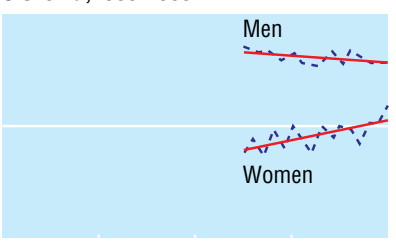

United Kingdom,1959-99

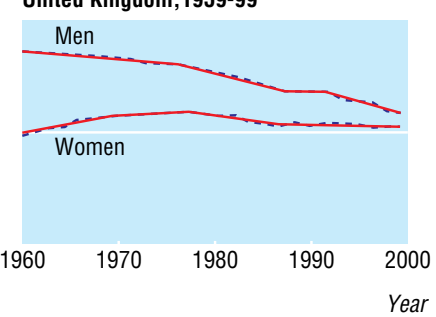
denote time trends calculated by software Joinpoint (http://srab.cancer.gov/joinpoint). Cyprus was not included in the analysis because of lack of data. 


\section{What is already known on this topic}

Lung cancer mortality among men is higher in central and eastern Europe than in the 15 original (western) states of the European Union

For each sex, lung cancer rates are distinctly higher in Hungary than elsewhere

\section{What this study adds}

Lung cancer mortality is now falling in middle aged men in all new EU states in central and eastern Europe but is still rising among women in most EU countries

found among men (Sweden, Denmark, and the Netherlands; figure).

\section{Comment}

Falling death rates due to lung cancer in the male populations of central and eastern Europe since at least the mid-1990s imply that trends in tobacco exposure in young men have been favourable since at least the early 1980s. The reasons for this need to be explored further and may include changes in prevalence, consumption, or modifications made to cigarettes since this time. ${ }^{4}$

Lung cancer epidemics among women show no consistent pattern that follows those in men, either in timing or in relative magnitude. This implies that the model advanced by Lopez et al in $1992^{5}$ is too simple in this respect. The very high mortality figures for Hungary merit further investigation.

When attention is focused not on the absolute rates, in men, of diseases caused by smoking but rather on the direction and magnitude of change in younger adults, new EU member states from central and eastern Europe are no longer at the bottom of the class. The favourable trends for men would also hold promise for future trends in women if these could be predicted from trends in men. However, these data show that this is unlikely to be the case, emphasising the continuing need for strong antismoking programmes for both sexes.

Contributors: JD conducted the analysis and cowrote the paper. MM conducted the analysis, cowrote, and edited the paper. $\mathrm{AMcN}$ and JP took part in editing the paper. WZ planned, conducted the analysis, wrote, and edited the paper. WZ is the guarantor.

Funding: This work was supported by the Closing the Gap Project, funded by the European Union Directorate for Health and Consumer Protection, Action 2003121.

Competing interests: None declared.

1 Peto R, Lopez AD, Boreham J, Thun M, Heath JrC. Mortality from smoking in developed countries 1950-2000. Oxford: Oxford University Press; 1994 Peto R, Darby S, Deo H, Silcocks P, Whitley E, Doll R. Smoking, smoking cessation, and lung cancer in the UK since 1950: combination of national statistics with two case-control studies. BMJ 2000;321:323-9.

3 Brennan P, Bray I. Recent trends and future directions for lung cancer mortality in Europe. Br J Cancer 2002;87:43-8.

4 Zatonski W. Tobacco smoking in central European countries: Poland. In: Boyle P, Gray N, Henningfield J, Seffrin J, Zatonski W, eds. Tobacco and public health: science and policy. Oxford: Oxford: University Press, 2004:235-52.

5 Lopez AD, Collishaw NE, Piha T. A descriptive model of the cigarette epidemic in developed countries. Tob Control 1994:3:243-7.

\title{
Commentary: Making the transition to action
}

\author{
Eva Kralikova, Erzsebet Podmaniczky, Hanna Stypułkowska-Misiurewicz, Elena Kavcova,
} Aurelijus Veryga, Tanith Muller

The news on smoking from the European Union's eastern frontiers is better than expected, with no evidence of a future gulf in lung cancer mortality between old and new member states. ${ }^{1}$ However, the special challenges faced by the eastern transitional economies-such as aggressive tobacco marketing, rapid liberalisation of the tobacco trade, and the political influence of the leading tobacco companies ${ }^{2}-$ remain. And a closer look at the study by Didkowska et $\mathrm{al}^{1}$ shows just how much work is still needed throughout the EU to reduce deaths from lung cancer and from other tobacco related disease.

The tobacco epidemic cannot be allowed to proceed without active intervention. Tobacco remains Europe's single biggest cause of preventable death. Lung cancer still accounts for more than a quarter of the EU's male cancer deaths and a rising number of deaths in women, ${ }^{3}$ and tobacco related diseases cause 650000 unnecessary deaths every year in the EU. ${ }^{4}$ Tobacco control has been identified as a priority in central and eastern Europe, ${ }^{3}$ but its importance cannot be restricted to these countries.

Throughout Europe, tobacco companies have proved adept at expanding and maintaining their mar- kets, especially among women. Marketing a life shortening addiction as liberation has proved a highly effective strategy in countries as diverse as Hungary, France, and Spain. There is no sign that the women's market has reached saturation point in most countries, and a far greater number of women will die if doctors and governments alike do not act. Despite having declined, tobacco related deaths in males remain frighteningly high.

The unpalatable truth is that both old and new EU states have made very limited progress in reducing tobacco use and its associated diseases in the past 50 years. Despite the evidence that half of all long term smokers will die prematurely as a result of smoking, ${ }^{5}$ both doctors and governments have found it hard to kick their addictions to tobacco. From those doctors whose own smoking stops them advising their patients to quit, to governments in thrall to tobacco companies' wealth, there can be no excuse for inaction.

The medical profession has a key role to play. Treatment for tobacco dependence is a cost effective intervention that will improve the health of patients who smoke; and doctors can advise governments as well as patients. Moreover, because
Institute of Hygiene and Epidemiology, Charles University,

Prague, Czech

Republic

Eva Kralikova

lecturer

Hungarian Medical Chamber, Budapest, Hungary

Erzsebet

Podmaniczk

president,

International

Relations Committee

Polish Chamber of

Physicians and

Dentists, Warsaw,

Poland

Hanna

Stypułkowska-Misiurewicz

international

relations officer

Department of

Tuberculosis and Respiratory

Diseases, Martin

Faculty Hospital,

Martin, Slovak

Republic

Elena Kavcova

lecturer

continued over 